\title{
The Formulation of Epidemic Prevention Work of COVID-19 for Colleges and Universities: Priorities and Recommendations
}

\author{
Wan-Chi Jackie Hsu ${ }^{1,2}$, Huai-Wei Lo ${ }^{3}$ (D) and Chin-Cheng Yang ${ }^{4,5, *}$ \\ 1 Graduate Institute of Cultural and Educational Management, Central Taiwan University of Sciences and \\ Technology, Taichung 40601, Taiwan; 108281@ctust.edu.tw \\ 2 College of Management, National Taipei University of Technology, Taipei 10608, Taiwan \\ 3 Department of Industrial Engineering and Management, Chaoyang University of Technology, \\ Taichung 413310, Taiwan; w110168888@gmail.com \\ 4 Department of Leisure Services Management, Chaoyang University of Technology, Taichung 413310, Taiwan \\ 5 Graduate School of Technological and Vocational Education, National Yunlin University of Science and \\ Technology, Yunlin 64002, Taiwan \\ * Correspondence: yccheng@cyut.edu.tw
}

Citation: Hsu, W.-C.J.; Lo, H.-W.; Yang, C.-C. The Formulation of Epidemic Prevention Work of COVID-19 for Colleges and Universities: Priorities and Recommendations. Sustainability 2021, 13, 2081. https://doi.org/ $10.3390 /$ su13042081

Academic Editor: José Gómez-Galán

Received: 11 January 2021

Accepted: 12 February 2021

Published: 15 February 2021

Publisher's Note: MDPI stays neutral with regard to jurisdictional claims in published maps and institutional affiliations.

Copyright: (c) 2021 by the authors. Licensee MDPI, Basel, Switzerland. This article is an open access article distributed under the terms and conditions of the Creative Commons Attribution (CC BY) license (https:// creativecommons.org/licenses/by/ $4.0 /)$.

\begin{abstract}
As the Coronavirus disease 2019 (COVID-19) epidemic spreads all over the world, governments of various countries are actively adopting epidemic prevention measures to curb the spread of the disease. However, colleges and universities are one of the most likely places for cluster infections. The main reason is that college students have frequent social activities, and many students come from different countries, which may very likely cause college campuses to be entry points of disease transmission. Therefore, this study proposes a framework of epidemic prevention work, and further explores the importance and priority of epidemic prevention works. First of all, 32 persons in charge of epidemic prevention from various universities in Taiwan were invited to jointly formulate a campus epidemic prevention framework and determined 5 dimensions and 36 epidemic prevention works/measures/criteria. Next, Bayesian best worst method (BWM) was used to generate a set of optimal group criteria weights. This method can not only integrate the opinions of multiple experts, but also effectively reduce the complexity of expert interviews to obtain more reliable results. The results show that the five most important measures for campus epidemic prevention are the establishment of a campus epidemic prevention organization, comprehensive disinfection of the campus environment, maintenance of indoor ventilation, proper isolation of contacts with confirmed cases, and management of immigration regulations for overseas students. This study provides colleges and universities around the world to formulate anti-epidemic measures to effectively reduce the probability of COVID-19 transmission on campuses to protect students' right to education.
\end{abstract}

Keywords: epidemic prevention; COVID-19; risk management; colleges and universities; Bayesian BWM

\section{Introduction}

If a systematic campus epidemic prevention guide can be established and provided to schools around the world as a reference, it can effectively reduce the risk of spreading Coronavirus disease 2019 (COVID-19) on campus and ensure students' right for education $[1,2]$. In order to reduce the spread of COVID-19, some countries prevent and control cross-infection by restricting contact among people. Governments of various countries recommend or order restrictions on social activities, including schooling. In order to slow the spread of the virus, colleges and universities have to be closed to protect students, teachers, and staff. Many college and universities have resorted to distance learning and online classes. However, the learning effect of distance teaching is not as good as in-person teaching [3]. In December 2019, the first outbreak of COVID-19 occurred in Wuhan, China. Many institutions and organizations have put forward emergency response guidelines for epidemic control. Since then, a series of COVID-19 prevention research has been greatly 
developed [4]. Unfortunately, research on campus epidemic prevention is still scarce. Most academic research is still centered on distance teaching and the psychological impact of students. If the virus infection can be effectively controlled, the university can restart the campus. Therefore, this study aims to develop a framework for the prevention of COVID-19 for colleges and universities. Specifically, the research scope and objectives of this study include the following:

(i) Identifying important epidemic prevention works, with the purpose of proposing a systematic hierarchical structure of campus epidemic prevention work/measure.

(ii) Integrating the opinions of multiple experts, and obtaining quantifiable information from the content of qualitative interviews through a multiple criteria decision-making (MCDM) approach.

(iii) Determining the priority order of epidemic prevention work, so as to provide suggestions for epidemic prevention in colleges and universities around the world.

In order to achieve the research objectives, this study uses the MCDM concept to construct an epidemic prevention assessment framework. The research of MCDM usually deals with decision-making problems in complex environments and seeks an ideal solution from numerous constraints or conflicting criteria. This method does not require large sample data as well as basic statistical assumptions [5]. Whether it is the qualitative data of expert interviews or the quantitative data obtained through measurement, MCDM can conduct an analysis and make summaries through some soft computing tools and provide effective management suggestions to support decision makers to formulate the ideal strategies [6].

The research process of this study can be briefly divided into two stages. First, we invited 32 persons in charge of epidemic prevention from colleges and universities to form a decision-making group. Most experts have experience in participating in the prevention of severe acute respiratory syndrome (SARS) in 2003. Therefore, the decisionmaking group is professional in campus epidemic prevention. The decision-making group conducted a literature review and screening of epidemic prevention works, and finally determined 36 criteria (epidemic prevention works). Next, this paper uses a new weight calculation method to determine the importance of the criteria, that is, the Bayesian best worst method (Bayesian BWM) [7]. Bayesian BWM optimizes the conventional BWM. It can effectively integrate the evaluation data of multiple experts to generate a set of optimal group weights and understand the consensus of all experts. The weight and priority of epidemic prevention works can be obtained. According to the management suggestions put forward in this study, it can reduce the time and cost of trial and error for colleges and universities that have not yet established epidemic prevention work, thereby reducing the infection rate of all personnel in colleges and universities. The overall advantages and contributions of this study are summarized as follows:

(i) A multiple criteria campus epidemic prevention framework is proposed to strengthen the epidemic prevention capabilities of colleges and universities.

(ii) Bayesian BWM is used to effectively integrate expert opinions to obtain more reliable results.

(iii) Anti-epidemic management recommendations for colleges and universities are provided to effectively reduce the infection of COVID-19.

(iv) The research process and structure are reproducible and referenceable, and serve as a reference for the epidemic prevention of relevant organizations and groups.

The rest of this paper is arranged as follows. Section 2 introduces the dimensions and criteria of COVID-19 prevention in colleges and universities. Section 3 describes the applied methodology and calculation procedures. Section 4 introduces the process of data collection and analysis. Section 5 discusses the results and explains the management implications. Section 6 summarizes the conclusions of the whole paper and provides future research works. 


\section{The Proposed Framework for Campus Epidemic Prevention}

This section explains the proposed framework for the prevention of COVID-19 by colleges and universities. The governments of some countries have implemented largescale lockdowns and used the media to promote the concept of "stay at home" to reduce the spread of COVID-19 [8]. Before the epidemic has slowed down, campus epidemic prevention work is even more important. To maintain the continuation of education, there must be a complete epidemic prevention mechanism to protect the health of students during school hours. In Taiwan, in order to effectively prevent the spread of COVID-19 on campus, the Ministry of Education of Taiwan has successively promulgated many campus epidemic prevention measures to maintain the public health of schools, including "the handling principles of 14-day home quarantine compiled by colleges and universities for students entering Taiwan with a history of travel in China, Hong Kong, and Macau", "precautions and reports for home quarantine of college students", "management and epidemic prevention measures for Hong Kong and Macau students", and "the outlines of the prevention and treatment of severe and special infectious pneumonia in colleges and universities" $[9,10]$. These guiding principles and epidemic prevention measures have all contributed to the epidemic prevention work of colleges and universities in Taiwan.

This study established a decision-making group to jointly formulate a framework for the epidemic prevention work of colleges and universities. A total of 32 persons in charge of epidemic prevention in Taiwan's colleges and universities were invited to participate in the formulation of the framework. Most of the experts have been in the academic field for more than 10 years, and approximately $72 \%$ of the experts have experience in SARS prevention in 2003. Table 1 presents the experts' academic qualifications, years of school service, and whether they have participated in SARS prevention.

Table 1. Statistics of expert background.

\begin{tabular}{cccc}
\hline Item & Category & No. of People & Percentage \\
\hline Education & Bachelor & 3 & $9.4 \%$ \\
& Master & 13 & $40.6 \%$ \\
& PhD & 16 & $50 \%$ \\
\hline Years of experience & $<5$ years & 1 & $3.1 \%$ \\
& $5-10$ years & 2 & $6.3 \%$ \\
& $>10$ years & 29 & $90.6 \%$ \\
\hline Participated in SARS prevention & Yes & 23 & $71.9 \%$ \\
& No & 9 & $28.1 \%$ \\
\hline
\end{tabular}

A total of 52 criteria were drafted in the initial campus epidemic prevention work framework. Through a Delphi method, the 32 experts were asked to select the epidemic prevention criteria they deem necessary. The Delphi questionnaire was distributed to experts at different times for review. Then, based on their experience, experts could propose other criteria that had not yet been proposed. After several meetings of the 32 experts have been held for revising and adjusting the definition of the criteria, the final framework was determined.

The final dimensions-criteria hierarchical structure is based on the epidemic prevention guidelines proposed by the Ministry of Education and the Ministry of Health and Welfare $[9,10]$. It can be classified into five main dimensions, including establishment of epidemic prevention organizations and control of campus epidemic $\left(D_{1}\right)$, formulation of campus epidemic prevention measures $\left(D_{2}\right)$, health management of faculty, staff, and students $\left(D_{3}\right)$, establishment of remote teaching and contingency measures $\left(D_{4}\right)$, and student extracurricular affairs management $\left(D_{5}\right)$. These dimensions can be divided into a total of 36 criteria. 


\subsection{Establishment of EpidemicPrevention Organization and Control of Campus Epidemic}

"Establishment of epidemic prevention organization and control of campus epidemic $\left(D_{1}\right)^{\prime \prime}$ is one of the most important dimensions of epidemic prevention work. Schools must systematically plan and coordinate all epidemic prevention matters in order to be able to deal with emergencies quickly. In addition, the top leaders of epidemic prevention must grasp the health status of all faculty and staff and confirm whether anyone has contracted COVID-19. The establishment of information systems, the planning of epidemic prevention budgets, the control of epidemic prevention materials, and thorough inspections of personnel entry and exit, etc., are all critical items in this dimension [11,12]. Table 2 introduces the criteria and descriptions included in $D_{1}$.

Table 2. Criteria and descriptions under $D_{1}$.

Criteria

Consolidation of campus epidemic prevention status $\left(C_{12}\right)$

Establishment of campus epidemic prevention information system $\left(C_{13}\right)$

\section{Description}

President, Vice-President, or Secretary-general serves as the convener or deputy convener, and Dean of General Affairs or Dean of Student Affairs serves as the chief executive officer to establish complete job duties and organizational structure for the epidemic prevention team.

All departments related to epidemic prevention can immediately and accurately grasp the implementation status of epidemic prevention measures.

Collection and dissemination of epidemic prevention information to provide the timely and accurate implementation of epidemic prevention measures. Using the school webpage announcement, each administrative office's dissemination, and mobile communication equipment to pass on the epidemic prevention notice.

The estimated expenditure during the epidemic prevention period includes arrangements for hardware facilities, information communications, and staple merchandise.

Complete planning and procurement of epidemic prevention supplies, including instruments for measuring body temperature, alcohol, wipes, masks, toilet paper, etc.

To avoid department failure caused by group infection in the same department, the staff seats among departments should be exchanged.

Establishment of health records of all faculty, staff, and students, including recent travel history, contact history, and current health status.

Plans for providing emotional counseling to faculty, staff, and students during the epidemic prevention period, or referring to other appropriate professional services.
Consultation and counseling plan during epidemic prevention $\left(C_{18}\right)$

\subsection{Formulation of Campus Epidemic Prevention Measures}

The requirements of campus sanitation and environmental sanitation cannot be ignored. "Formulation of campus epidemic prevention measures $\left(D_{2}\right)$ " focuses on the sanitation and safety of the entry and exit of all personnel and the environment. Surveillance should be strengthened around the campus to prevent loopholes in epidemic prevention. All hardware equipment and public activity spaces must be disinfected, including restaurants, classrooms, stadiums, buses, etc. [13,14]. In addition, the entry and exit of visitors outside the school must be strictly controlled, and non-school personnel must be prohibited from entering when necessary [11]. Some specific works are presented in Table 3. 
Table 3. Criteria and descriptions under $D_{2}$.

\begin{tabular}{|c|c|}
\hline Criteria & Description \\
\hline Enhancing the fence around the campus $\left(C_{21}\right)$ & $\begin{array}{l}\text { Installing fences around the campus to prevent non-school } \\
\text { faculty, staff, and students from entering. }\end{array}$ \\
\hline Establishment of temperature check station $\left(C_{22}\right)$ & $\begin{array}{l}\text { Setting up body temperature measurement stations at the } \\
\text { entrance and exit of the campus. Those over } 37.5 \text { degrees are } \\
\text { prohibited from entering the campus, and the school provides } \\
\text { medical assistance. }\end{array}$ \\
\hline Restrictions on external visitors $\left(C_{23}\right)$ & $\begin{array}{l}\text { Promoting that external visitors use the telephone, video } \\
\text { conferencing, mobile communication, and other equipment to } \\
\text { contact for official business. }\end{array}$ \\
\hline External visitor access management $\left(C_{24}\right)$ & $\begin{array}{l}\text { Measuring, inquiring, and recording the body temperature, } \\
\text { travel history, and places visited at the entrance on the premise } \\
\text { that external visitors must enter the campus for official business. }\end{array}$ \\
\hline Indoor space ventilation management $\left(C_{25}\right)$ & $\begin{array}{l}\text { Keeping ventilation in various offices and classrooms. When the } \\
\text { ventilation is not good, electric fans or exhaust fans should be } \\
\text { installed to enhance air convection. }\end{array}$ \\
\hline Public transportation vehicle hygiene management $\left(C_{26}\right)$ & $\begin{array}{l}\text { Implementing disinfection measures on public transportation } \\
\text { vehicles near the campus, and a clear disinfection record is } \\
\text { required every day. }\end{array}$ \\
\hline Control of people and tables in the restaurants on campus $\left(C_{27}\right)$ & $\begin{array}{l}\text { Controlling the number of people dining in the restaurants on } \\
\text { campus, and setting partitions for dining tables. }\end{array}$ \\
\hline Disinfection of campus environment $\left(C_{28}\right)$ & $\begin{array}{l}\text { Regular disinfection of indoor spaces, public areas, public } \\
\text { equipment, dormitories, etc. }\end{array}$ \\
\hline
\end{tabular}

\subsection{Health Management of Faculty, Staff and Students}

The personal hygiene and health status of faculty, staff, and students are evaluated by the "Health management of faculty, staff, and students $\left(D_{3}\right)$ " dimension. In this dimension, the proposed works are based on the premise that there are no cases or only a few cases. The Ministry of Health and Welfare has repeatedly echoed the importance of self-health management to the public through media communication and other means. The school must also strengthen publicity to require students to manage self-health. More importantly, once people who have been in contact with a confirmed case are found, the school must notify the relevant government unit as soon as possible and bring them to hospitals for testing and treatment [14-16]. Table 4 lists the criteria and descriptions of $D_{3}$.

\subsection{Establishment of Remote Teaching and Contingency Measures}

If there is unfortunately a case of COVID-19 infection on the campus, it is necessary to take immediate contingency measures and conduct remote teaching to maintain the student's right to education. "Establishment of remote teaching and contingency measures $\left(D_{4}\right)^{\prime \prime}$ focuses on enrollment and teaching quality to ensure that the school can operate stably and teach safely. In addition, the immigration management of foreign students is an urgent task to prevent foreign students from bringing the virus into Taiwan [17-19]. Table 5 gives specific suggestions on how to respond.

\subsection{Student Extracurricular Affairs Management}

"Student extracurricular affairs management $\left(D_{5}\right)$ " includes gatherings, student organization activities, and internships. To reduce the chance of group infection, the handling of each activity should be carefully evaluated and reviewed before deciding whether to continue according to the original plan [20-22]. Table 6 lists the criteria and descriptions included in $D_{5}$. 
Table 4. Criteria and descriptions under $D_{3}$.

Criteria

Notification of Suspected/confirmed cases $\left(C_{31}\right)$
Description

If a suspected or confirmed case is found, the school should immediately implement the campus infectious disease notification procedure, and cooperate with the regulations of the Department of Disease Control of the Ministry of Health and Welfare of the Executive Yuan to notify and seek medical treatment

Requirements for wearing masks for all faculty, staff, and students of the school $\left(C_{32}\right)$

All faculty, staff, and students must wear masks when entering the campus.

A distance of $1.5 \mathrm{~m}$ is required to maintain without wearing a mask $\left(C_{33}\right)$

A social distance of $1.5 \mathrm{~m}$ is required to maintain without wearing a mask.

Strengthening the awareness of personal hygiene habits, such as washing hands frequently, covering mouth and nose when Strengthening of personal hygiene practices $\left(C_{34}\right)$ sneezing and coughing, and properly handling mouth and nose secretions.

The homeroom teachers or instructors should pay attention to whether the students have a fever, cough, or non-allergic runny nose and other respiratory conditions. If symptoms show up, they should immediately report to the Health Center and ask the students to go to the Health Center to request medical assistance.

Once visiting a crowded place during consecutive holidays, faculty, staff, and students should always pay attention to their physical condition.

Self-health management at the end of consecutive holidays $\left(C_{36}\right)$

Tracking those who enter Taiwan from abroad after returning to school $\left(C_{37}\right)$

Faculty, staff, and students returning from abroad must undergo 14 days of home quarantine. When returning to school after quarantine, they must continue to track their health and records.

Those who have been in contact with a confirmed case should be listed as contacts of the confirmed case, and the health unit shall issue a home quarantine notice for the contacts and be

quarantined until 14 days after the date of the most recent contact with the confirmed case. When returning to school after quarantine, they must continue to track their health and records.

Table 5. Criteria and descriptions under $D_{4}$.

\begin{tabular}{|c|c|}
\hline Criteria & Description \\
\hline Simulation and improvement of remote teaching $\left(C_{41}\right)$ & $\begin{array}{l}\text { The pre-work preparation for remote teaching is through } \\
\text { repeated simulations and improvements to maintain the quality } \\
\text { of teaching. }\end{array}$ \\
\hline $\begin{array}{l}\text { If the school has } 2 \text { confirmed cases, all of the classes must be } \\
\text { suspended }\left(C_{42}\right)\end{array}$ & $\begin{array}{l}\text { Handling the suspension of classes following the suspension } \\
\text { standards of the Central Epidemic Command Center, and } \\
\text { reporting in accordance with the notification process. At that } \\
\text { time, the school-wide remote teaching will be implemented. }\end{array}$ \\
\hline $\begin{array}{l}\text { Formulating measures for the management of foreign } \\
\text { students }\left(C_{43}\right)\end{array}$ & $\begin{array}{c}\text { The investigation before/after entry of foreign students, } \\
\text { including arrangements for pick-up after entry, publicity, and } \\
\text { monitoring and notification operations. }\end{array}$ \\
\hline
\end{tabular}


Table 5. Cont.

\begin{tabular}{cc}
\hline Criteria & Description \\
\hline $\begin{array}{c}\text { Formulating contingency measures for admissions } \\
\text { examination }\left(C_{44}\right)\end{array}$ & $\begin{array}{c}\text { Publicizing in advance the test measures for the examinees } \\
\text { during the epidemic prevention period, and planning alternate } \\
\text { test sites to respond to emergencies. }\end{array}$ \\
\hline $\begin{array}{c}\text { Formulating contingency measures for interview and } \\
\text { selection }\left(C_{45}\right)\end{array}$ & $\begin{array}{c}\text { Formulating methods for holding interviews and selection in } \\
\text { accordance with changes in the epidemic. }\end{array}$ \\
\hline $\begin{array}{c}\text { Formulation of make-up lessons (or class resumption) and } \\
\text { performance evaluation flexibility measures }\left(C_{46}\right)\end{array}$ & $\begin{array}{c}\text { Formulating measures for students to make up classes after } \\
\text { classes are suspended and measures for flexibility in } \\
\text { performance evaluation to ensure student rights. }\end{array}$ \\
\hline
\end{tabular}

Table 6. Criteria and descriptions under $D_{5}$.

Criteria Description

Stop holding large-scale gatherings on campus $\left(C_{51}\right)$

Large-scale events will be monitored or postponed. If they need to be held, please follow the "Central Epidemic Command Center COVID-19 (Severe Special Infectious Pneumonia) Response Guidelines: Public Assembly" for related matters.

Establishing the activity risk assessment form. Non-large-scale

Establishing a risk assessment system for small gatherings $\left(C_{52}\right)$ gatherings must undergo a risk assessment before deciding whether to proceed.

Formulation of rules for the use of venues for gatherings $\left(C_{53}\right)$

Formulation of measures for the off-campus internship (domestic) $\left(C_{54}\right)$

Formulation of measures for overseas internships (overseas) $\left(C_{55}\right)$
Disinfection before and after use of the venue, real-name registration of participants, body temperature measurement of personnel entering the venue and hand sanitation actions, etc.

During the epidemic prevention period, the school will assist in the flexible adjustment of off-campus internship contracts and provide alternatives for insufficient internship hours.

Students' overseas internships should be completely canceled. If the internships are already in progress, students need to contact their local diplomatic offices to request assistance in returning to Taiwan.

Formulation of home quarantine measures for dormitories on campus $\left(C_{56}\right)$
Formulation of relevant measures and procedures of home quarantine in dormitories on campus for students.

\section{Bayesian BWM}

BWM was proposed by Rezaei [23]. It aims to improve the two shortcomings of AHP, including reducing the number of pairwise comparisons and obtaining better consistency results. Assuming that an evaluation system has $n$ criteria, AHP requires $n(n-1) / 2$ pairwise comparisons, but BWM only requires $2 n-3$ times. The operating concept of BWM is very simple. First, the best and worst criteria are selected. Then, the best criterion is compared with other criteria to obtain the BO (Best-to-Others) vector. Similarly, other criteria are used to compare with the worst criteria to form an OW (Others-to-Worst) vector. The judgment provided by each expert is not necessarily the same. If different best and worst criteria are selected, the meaning of the formed vectors information is different. If the arithmetic average is used to aggregate the opinions of multiple experts, some information will be lost [3]. Mohammadi and Rezaei [7] proposed a method of using a statistical probability model to determine weights, which finds the optimal group criteria weights in the probability distribution environment. Suppose there are $n$ criteria in a specific evaluation system, namely $c_{j}, j=1,2, \ldots, n$. In addition, $w_{j}$ is expressed as the weight of criterion $c_{j}$. From a statistical point of view, the criterion $c_{j}$ is a random event, and the weight $w_{j}$ is the probability of a random event. In probability theory, it is required that $\sum_{j=1}^{n} w_{j}=1$ and $w_{j} \geq 0$, which are fully consistent with the concept of MCDM. There have been many studies using Bayesian BWM to discuss the weight determination of 
various issues. For example, hospital waste management [24], sustainable sports tourism development [4], business risk assessment [25], etc. The detailed Bayesian BWM execution steps and inference steps are as follows:

Step 1: Determining the evaluation framework and the criteria included.

The decision-making group draws up a hierarchical structure for the evaluation. The structure contains $n$ appropriate criteria, namely $c_{j}, j=1,2, . ., n$. In this paper, epidemic prevention works are regarded as criteria.

Step 2: Each expert selects the best and worst criteria based on their own judgment.

The evaluation framework proposed in the study is divided into 5 dimensions, so the BWM questionnaire survey must be performed 6 times (the importance of the dimensions and the importance of the criteria under each dimension). When each expert implements BWM, he/she chooses the most important and least important criteria. The most important and least important criteria selected by each expert can be different.

Step 3: The best criterion B is compared with other criteria $j$.

Before the pairwise comparisons of criteria, the importance scale should be set first. Its linguistic variables are shown in Table 7 [23]. Experts evaluate the importance of the best criterion $B$ to other criteria $j\left(a_{B j}\right)$ to generate $\mathrm{BO}$ vector, which is expressed as:

$$
A_{B j}=\left(a_{B 1}, a_{B 2}, \ldots, a_{B j}, \ldots, a_{B n}\right) .
$$

Table 7. The scale of the best worst method (BWM) evaluation.

\begin{tabular}{ccc}
\hline Linguistic Variables & Code & Crisp \\
\hline Equally important & E & 1 \\
Equal to moderately more important & Between E to MM & 2 \\
Moderately more important & MM & 3 \\
Moderately to strongly more important & Between MM to SM & 4 \\
Strongly more important & SM & 5 \\
Strongly to very strongly more important & Between SM to VSM & 6 \\
Very strongly more important & VSM & 7 \\
Very strongly to extremely more important & Between VSM to EM & 8 \\
Extremely more important & EM & 9 \\
\hline
\end{tabular}

Step 4: Similar to step 3, other criteria j is compared to the worst criterion $W$.

Experts evaluate the importance of other criteria $j$ to the worst criterion $W\left(a_{j W}\right)$ to generate $\mathrm{OW}$ vector, which is expressed as:

$$
A_{j W}=\left(a_{1 W}, a_{2 W}, \ldots, a_{j W}, \ldots, a_{n W}\right)^{T} .
$$

Here, the scale required for self-comparison is "Equally important, E", namely $a_{B B}=1$ and. $a_{W W}=1$.

Step 5: Generating the optimal group weight values of the criteria.

Since the elements of $A_{B j}$ and $A_{j W}\left(a_{B j}\right.$ and $\left.a_{j W}\right)$ are all positive integers, the probability mass density function of the polynomial distribution of $A_{j W}$ is recorded as:

$$
P\left(A_{j W} \mid w_{j}\right)=\frac{\left(\sum_{j=1}^{n} a_{j W}\right) !}{\prod_{j=1}^{n} a_{j W} !} \prod_{j=1}^{n} w_{j}^{a_{j W}} .
$$


where $w_{j}$ is the weight probability distribution of criterion $j$. The probability of $w_{j}$ is proportional to the number of occurrences and the total number of experiments $\left(a_{j W}\right)$, as shown in Equation (4).

$$
w_{j} \propto \frac{a_{j W}}{\sum_{j=1}^{n} a_{j W}}, \forall j=1,2, \ldots, n .
$$

If Equation (4) is reasonable, $a_{W W}=1$ is substituted into Equation (4), then $w_{W}$ is as shown in Equation (5).

$$
w_{W} \propto \frac{a_{W W}}{\sum_{j=1}^{n} a_{j W}}=\frac{1}{\sum_{j=1}^{n} a_{j W}} .
$$

Equations (4) and (5) are combined to get Equation (6).

$$
\frac{w_{j}}{w_{W}} \propto a_{j W}, \forall j=1,2, \ldots, n .
$$

Equation (6) echoes the concept of conventional BWM. However, the information acquisition methods of $A_{B j}$ and $A_{j W}$ are different. The former is that criterion $B$ is compared to criterion $j$. The larger $a_{B j}$ is, the smaller $w_{j}$ will be; the latter is that criterion $j$ is compared to criterion $W$, and the larger $A_{j W}$ is, the larger $w_{j}$ will be. Therefore, $A_{B j}$ and $w_{j}$ have a reciprocal relationship, as shown in Equations (7) and (8).

$$
\begin{gathered}
A_{B j} \sim \text { multinomial }\left(\frac{1}{w_{j}}\right) ; \\
\frac{1}{w_{j}} \propto \frac{a_{B j}}{\sum_{j=1}^{n} a_{B j}}, \forall j=1,2, \ldots, n .
\end{gathered}
$$

Similarly, if $a_{W W}=1$ is substituted into Equation (8), then $w_{B}$ is shown in Equation (9).

$$
\frac{1}{w_{B}} \propto \frac{a_{B B}}{\sum_{j=1}^{n} a_{B j}}=\frac{1}{\sum_{j=1}^{n} a_{B j}} \Rightarrow \frac{w_{B}}{w_{j}} \propto a_{B j}, \forall j=1,2, \ldots, n .
$$

Dirichlet probability distribution meets the requirements of MCDM (the weight is greater than or equal to 0 , and the total weight is equal to 1 ), so the Dirichlet probability distribution is used to construct the model, as shown in Equation (10).

$$
\operatorname{Dir}\left(w_{j} \mid \alpha\right)=\frac{1}{B(\alpha)} \prod_{j=1}^{n} w_{j}^{\alpha_{j}-1}
$$

where $\alpha$ is a vector parameter. Here, $\alpha$ is set to 1 , because this parameter does not affect the prior probability.

Using the Dirichlet probability distribution model to regard $w_{j}$ as the prior probability distribution, and then, based on the Dirichlet distribution $w_{j}$ for Bayesian estimation, the posterior probability distribution model is

$$
\mu_{j}=\frac{\alpha_{\text {post }, t_{j}}-1}{\sum_{j=1}^{n} \alpha_{\text {post }, t_{j}}-n}=\frac{1+a_{j W}-1}{\sum_{j=1}^{n}\left(a_{j W}+1\right)-n}=\frac{a_{j W}}{\sum_{j=1}^{n} a_{j W}} .
$$

where $\alpha_{\text {post }}=\alpha+A_{W j}=1+A_{W j}$ and $A_{W}=\left(a_{j W}\right)=\left(a_{1 W}, a_{2 W}, \ldots, a_{j W}, \ldots, a_{n W}\right)$.

Next, the steps of Bayesian BWM integrating the evaluation data of multiple experts are as follows:

Step 5.1: Constructing a joint probability distribution.

Suppose there are $j$ criteria, $k$ experts, $j=1,2, . ., n ; k=1,2, \ldots, K$. The weight of each criterion generated by each expert is $w_{j}^{k}$, and the weight of the integrated group is $w_{j}^{a g g}$. The $\mathrm{BO}$ vectors of all experts can be constructed into a matrix such as $A_{B j}^{1: K}$. Similarly, $A_{j \mathrm{~W}}^{1: K}$ 
represents the OW vector of all experts. $A_{B j}^{1: K}$ and $A_{j W}^{1: K}$ are based on the data surveyed by expert interviews to construct a joint probability distribution, as shown in Equation (12).

$$
P\left(w_{j}^{a g g}, w_{j}^{1: K} \mid A_{B j}^{1: K}, A_{j W}^{1: K}\right) .
$$

Step 5.2: Development and calculation of the Bayesian hierarchical model.

Each expert's $A_{B j}$ and $A_{j W}$ will generate the weight $w_{j}^{k}$, and the group's weight depends on each expert. The calculation logic of Bayesian is to obtain the final weight through continuous iteration. After the evaluation data of each expert is entered, Bayesian BWM will continuously update to the group's weight $w_{j}^{a g g}$, and the joint probability of the Bayesian model is shown in Equations (13) and (14).

$$
\begin{array}{r}
P\left(w_{j}^{a g g}, w_{j}^{1: K} \mid A_{B j}^{1: K}, A_{j W}^{1: K}\right) \propto P\left(A_{B j}^{1: K}, A_{j W}^{1: K} \mid w_{j}^{a g g}, w_{j}^{1: K}\right) P\left(w_{j}^{a g g}, w_{j}^{1: K}\right) ; \\
P\left(A_{B j}^{1: K}, A_{j W}^{1: K} \mid w_{j}^{a g g}, w_{j}^{1: K}\right) P\left(w_{j}^{a g g}, w_{j}^{1: K}\right)=P\left(w_{j}^{a g g}\right) \prod_{k=1}^{K} P\left(A_{j W}^{k} \mid w_{j}^{k}\right) P\left(A_{B j}^{k} \mid w_{j}^{k}\right) P\left(w_{j}^{k} \mid w_{j}^{a g g}\right) .
\end{array}
$$

From Equation (14), the Dirichlet distribution of $w_{j}^{k}$ under the condition of $w_{j}^{a g g}$ can be constructed, as shown in Equation (15).

$$
w_{j}^{k} \mid w_{j}^{a g g} \sim \operatorname{Dir}\left(\gamma \times w_{j}^{a g g}\right), \forall_{k}=1,2, \ldots, K .
$$

where $w_{j}^{a g g}$ is the average of Dirichlet distribution, and $\gamma$ is a non-negative parameter. $w_{j}^{k}$ will approximate $w_{j}^{a g g}$ to the average value of the Dirichlet distribution, and the degree of approximation is determined by the parameter $\gamma$, as shown in Equation (16). This method is an important operation of the Bayesian model [26].

$$
\gamma \sim \operatorname{gamma}(a, b) .
$$

where $a$ and $b$ are the shape and scale parameters assigned by gamma.

Finally, $\alpha$ is set to $1 w_{j}^{a g g}$ will obey the Dirichlet allocation, as shown in Equation (17).

$$
w_{j}^{a g g} \sim \operatorname{Dir}(\alpha) .
$$

Bayesian BWM uses the Markov-chain Monte Carlo (MCMC) technique to simulate continuously to calculate the posterior probability distribution to obtain the optimal group weight $w_{j}^{\text {agg }}$.

Step 6: Calculate ranking confidence.

After Bayesian BWM calculations, the researchers must understand whether the generation of $w_{j}^{a g g}$ is consistent with the opinions of all experts. We use the concept of Credal Ranking to examine its confidence. Suppose there are two criteria, namely $c_{\theta}$ and $c_{\lambda}$. Then the probability that $c_{\theta}$ is better than $c_{\lambda}$ is shown in Equation (18).

$$
P\left(c_{\theta}>c_{\lambda}\right)=\int I\left(w_{\theta}^{a g g}>w_{\lambda}^{a g g}\right) P\left(w_{j}^{a g g}\right) .
$$

where $P\left(w_{j}^{a g g}\right)$ is the posterior probability of $w_{j}^{a g g}$, and I is the conditional parameter, and it can be calculated only when $\left(w_{\theta}^{a g g}>w_{\lambda}^{a g g}\right)$ is true, otherwise, it is 0 . The rank- 
ing confidence is calculated by the sample number $\mathrm{Q}$ obtained by MCMC, as shown in Equations (19) and (20).

$$
\begin{aligned}
& P\left(c_{\theta}>c_{\lambda}\right)=\frac{1}{Q} \sum_{q=1}^{Q} I\left(w_{\theta}^{a g g_{q}}>w_{\lambda}^{a g g_{q}}\right) ; \\
& P\left(c_{\lambda}>c_{\theta}\right)=\frac{1}{Q} \sum_{q=1}^{Q} I\left(w_{\lambda}^{a g g_{q}}>w_{\theta}^{a g g_{q}}\right) .
\end{aligned}
$$

where $w_{j}^{a g g_{q}}$ represents $\mathrm{q} w^{a g g}$ 's from MCMC samples. The higher the ranking confidence, the better, which means that experts have a consensus on the importance of the criteria. For a more detailed introduction of Bayesian BWM, please refer to Mohammadi and Rezaei [7].

\section{Data Collection, Treatment, and Analysis}

Bayesian BWM is used to calculate the survey data of this research, and through the valuable epidemic prevention experience of 32 experts, to understand which epidemic prevention criteria are urgent. After the SARS outbreak in 2003, the Taiwanese government paid special attention to the prevention of cross-infection during social activities. Therefore, many private enterprises, organizations, institutions, and groups have formulated preventive measures against serious infectious diseases. Proper use of personal protective equipment and the implementation of infection control measures may help reduce the spread of SARS-CoV-2. Currently, colleges and universities in Taiwan have made many contributions to epidemic control.

According to the framework proposed in Section 2, Bayesian BWM is used for calculation and analysis. Researchers designed the Bayesian BWM questionnaire for this study. During the interview, the concept of Bayesian BWM and the type of input data were explained in detail. After confirming that the experts understood the content and interview procedures, the researchers began to ask questions and record responses. First, each expert is asked to select the best and worst dimensions/criteria. Next, they conduct an evaluation according to the linguistic variables presented in Table 7 to obtain $A_{B j}^{1: K}$ and $A_{j W}^{1: K}$.

We use the calculation of dimensions to make an explanation. The interview data of 32 experts are shown in Tables 8 and 9 (the linguistic variables have been converted into crisp values). In Table 8 , the first expert considers $D_{3}$ to be the best criterion $\mathrm{B}$, and compares $D_{3}$ with other criteria $j$, thus generating a $\mathrm{BO}$ vector $A_{B j}^{1}=(1,3,1,3,2)$, which means that the importance of $D_{3}$ is the same as that of $D_{1}$, and the importance of $D_{3}$ is about 3 times that of $D_{2}$. The rest can be done in the same manner. Besides, the data in Table 9 have undergone matrix transposition, so the interpretation direction is opposite to the $\mathrm{BO}$ vector. $D_{4}$ is considered as the worst criterion. Comparing other criteria $j$ with $D_{4}$, the generated OW vector is $A_{j W}^{1}=(3,1,3,1,2)$, which means that the importance of $D_{4}$ is about 3 times that of $D_{1}$, and the importance of $D_{4}$ and $D_{2}$ is equal.

All experts answered the BWM questionnaire in the same way, and the information obtained was two $32 \times 5$ matrices (Tables 8 and 9). The criteria under each dimension are similar to the above examples to operate. Therefore, an expert needs to fill out 6 questionnaires. Before the implementation of Bayesian BWM, each BWM questionnaire would be checked for consistency. This step is to ensure the logic and reliability of each expert when they fill out the questionnaire. The average consistency ratio of all the questionnaires is 0.023, indicating a high degree of consistency [23].

In this study, the MATLAB program provided by Mohammadi and Rezaei [7] was adopted as the Bayesian BWM calculation software. The Bayesian BWM results are shown in Table 10. In the dimension part, Health management of faculty, staff, and students $\left(D_{3}\right)$ is the most important factor in the prevention of COVID-19 in colleges and universities (the weight is 0.245), emphasizing that personal health management and hygiene awareness are more important than other dimensions. In addition, looking at the overall evaluation results, it can be seen that the top five are Disinfection of campus environment $\left(C_{28}\right)$, 
putting those in close contacts with confirmed cases in quarantine $\left(C_{38}\right)$, indoor space ventilation management $\left(C_{25}\right)$, establishment of campus epidemic prevention team $\left(C_{11}\right)$, and formulation of measures for the management of overseas students $\left(C_{43}\right)$. Further discussion and management implications will be presented in Section 5.

The confidence test of ranking is to check whether the obtained analysis results meet the consensus of most experts. Taking dimensions as an example, the confidence matrix of ranking can be established according to Equations (18)-(20), as shown in Table 11. For example, the confidence that $D_{1}$ is more important than $D_{2}$ is $27.02 \%$, and the confidence that $D_{2}$ is more important than $D_{1}$ is $72.97 \%$, indicating that most experts believe that $D_{2}$ is more important than $D_{1}$. It is worth mentioning that the difference in confidence between $D_{2}$ and $D_{3}$ is not that much, indicating that the importance of $D_{2}$ and $D_{3}$ is quite similar. We observe that the weights of the two dimensions are 0.240 and 0.245 , respectively. This result shows that the confidence can correspond to the weight of Bayesian BWM. In general, the average consensus of the experts is as high as $87.25 \%$, including dimensions and all criteria, indicating that the analysis results of the study are reliable.

Table 8. The most important dimensions selected by 32 experts and the Best-to-Others (BO) vectors.

\begin{tabular}{lcccccc}
\hline Expert & Best & $\boldsymbol{D}_{\mathbf{1}}$ & $\boldsymbol{D}_{\mathbf{2}}$ & $\boldsymbol{D}_{\mathbf{3}}$ & $\boldsymbol{D}_{\mathbf{4}}$ & $\boldsymbol{D}_{\mathbf{5}}$ \\
\hline No. 1 & $D_{3}$ & 1 & 3 & 1 & 3 & 2 \\
No. 2 & $D_{3}$ & 1 & 1 & 1 & 1 & 1 \\
No. 3 & $D_{2}$ & 2 & 1 & 1 & 2 & 3 \\
No. 4 & $D_{2}$ & 2 & 1 & 1 & 3 & 4 \\
No. 5 & $D_{3}$ & 1 & 1 & 1 & 1 & 4 \\
No. 6 & $D_{3}$ & 1 & 1 & 1 & 1 & 1 \\
No. 7 & $D_{3}$ & 1 & 1 & 1 & 1 & 1 \\
No. 8 & $D_{3}$ & 1 & 1 & 1 & 3 & 4 \\
No. 9 & $D_{3}$ & 1 & 1 & 1 & 1 & 1 \\
No. 10 & $D_{1}$ & 1 & 1 & 1 & 1 & 1 \\
No. 11 & $D_{1}$ & 1 & 1 & 1 & 1 & 1 \\
No. 12 & $D_{1}$ & 1 & 1 & 1 & 5 & 1 \\
No. 13 & $D_{1}$ & 1 & 1 & 1 & 1 & 1 \\
No. 14 & $D_{3}$ & 1 & 1 & 1 & 1 & 5 \\
No. 15 & $D_{3}$ & 1 & 1 & 1 & 1 & 1 \\
No. 16 & $D_{2}$ & 2 & 1 & 2 & 2 & 2 \\
No. 17 & $D_{3}$ & 1 & 1 & 1 & 1 & 1 \\
No. 18 & $D_{3}$ & 1 & 1 & 1 & 3 & 5 \\
No. 19 & $D_{2}$ & 5 & 1 & 1 & 3 & 3 \\
No. 20 & $D_{1}$ & 1 & 1 & 1 & 1 & 1 \\
No. 21 & $D_{1}$ & 1 & 1 & 1 & 1 & 5 \\
No. 22 & $D_{1}$ & 1 & 1 & 1 & 1 & 1 \\
No. 23 & $D_{2}$ & 3 & 1 & 1 & 4 & 4 \\
No. 24 & $D_{3}$ & 1 & 1 & 1 & 3 & 3 \\
No. 25 & $D_{3}$ & 1 & 1 & 1 & 1 & 1 \\
No. 26 & $D_{3}$ & 1 & 1 & 1 & 1 & 1 \\
No. 27 & $D_{1}$ & 1 & 2 & 2 & 2 & 3 \\
No. 28 & $D_{1}$ & 1 & 1 & 1 & 1 & 1 \\
No. 29 & $D_{3}$ & 1 & 1 & 1 & 3 & 1 \\
No. 30 & $D_{3}$ & 1 & 1 & 1 & 1 & 1 \\
No. 31 & $D_{1}$ & 1 & 1 & 1 & 1 & 4 \\
No. 32 & $D_{3}$ & 1 & 1 & 1 & 1 & 1 \\
\hline & & & & & &
\end{tabular}


Table 9. The least important dimensions selected by 32 experts and the Others-to-Worst $(\mathrm{OW})$ vectors (the content of this table has been matrix transposed).

\begin{tabular}{lcccccc}
\hline Expert & Worst & $\boldsymbol{D}_{\mathbf{1}}$ & $\boldsymbol{D}_{\mathbf{2}}$ & $\boldsymbol{D}_{\mathbf{3}}$ & $\boldsymbol{D}_{\mathbf{4}}$ & $\boldsymbol{D}_{\mathbf{5}}$ \\
\hline No. 1 & $D_{4}$ & 3 & 1 & 3 & 1 & 2 \\
No. 2 & $D_{5}$ & 1 & 1 & 1 & 1 & 1 \\
No. 3 & $D_{5}$ & 2 & 3 & 3 & 2 & 1 \\
No. 4 & $D_{5}$ & 2 & 4 & 4 & 2 & 1 \\
No. 5 & $D_{5}$ & 4 & 4 & 4 & 4 & 1 \\
No. 6 & $D_{5}$ & 1 & 1 & 1 & 1 & 1 \\
No. 7 & $D_{5}$ & 1 & 1 & 1 & 1 & 1 \\
No. 8 & $D_{5}$ & 4 & 4 & 4 & 2 & 1 \\
No. 9 & $D_{5}$ & 1 & 1 & 1 & 1 & 1 \\
No. 10 & $D_{4}$ & 1 & 1 & 1 & 1 & 1 \\
No. 11 & $D_{4}$ & 1 & 1 & 1 & 1 & 1 \\
No. 12 & $D_{4}$ & 5 & 5 & 5 & 1 & 5 \\
No. 13 & $D_{5}$ & 1 & 1 & 1 & 1 & 1 \\
No. 14 & $D_{5}$ & 5 & 5 & 5 & 5 & 1 \\
No. 15 & $D_{5}$ & 1 & 1 & 1 & 1 & 1 \\
No. 16 & $D_{5}$ & 1 & 2 & 1 & 1 & 1 \\
No. 17 & $D_{4}$ & 1 & 1 & 1 & 1 & 1 \\
No. 18 & $D_{5}$ & 5 & 5 & 5 & 3 & 1 \\
No. 19 & $D_{1}$ & 1 & 5 & 5 & 3 & 3 \\
No. 20 & $D_{5}$ & 1 & 1 & 1 & 1 & 1 \\
No. 21 & $D_{5}$ & 5 & 5 & 5 & 5 & 1 \\
No. 22 & $D_{4}$ & 1 & 1 & 1 & 1 & 1 \\
No. 23 & $D_{5}$ & 2 & 4 & 4 & 1 & 1 \\
No. 24 & $D_{5}$ & 3 & 3 & 3 & 1 & 1 \\
No. 25 & $D_{5}$ & 1 & 1 & 1 & 1 & 1 \\
No. 26 & $D_{5}$ & 1 & 1 & 1 & 1 & 1 \\
No. 27 & $D_{5}$ & 3 & 2 & 2 & 2 & 1 \\
No. 28 & $D_{4}$ & 1 & 1 & 1 & 1 & 1 \\
No. 29 & $D_{4}$ & 3 & 3 & 3 & 1 & 3 \\
No. 30 & $D_{5}$ & 1 & 1 & 1 & 1 & 1 \\
No. 31 & $D_{5}$ & 4 & 1 & 1 & 1 & 1 \\
No. 32 & $D_{5}$ & 1 & 1 & 1 & 1 & 1 \\
\hline & & & & & & \\
\hline
\end{tabular}

Table 10. Results of Bayesian BWM: The dimensions and criteria weights for the 32 experts.

\begin{tabular}{|c|c|c|c|c|c|c|c|}
\hline Dimension & Local Weight & Rank & Criteria & Local Weight & Rank & Global Weight & Rank \\
\hline \multirow[t]{8}{*}{$D_{1}$} & 0.220 & 3 & $C_{11}$ & 0.160 & 1 & 0.035 & 4 \\
\hline & & & $C_{12}$ & 0.154 & 2 & 0.034 & 10 \\
\hline & & & $C_{13}$ & 0.149 & 3 & 0.033 & 12 \\
\hline & & & $C_{14}$ & 0.148 & 4 & 0.032 & 13 \\
\hline & & & $C_{15}$ & 0.130 & 5 & 0.029 & 18 \\
\hline & & & $C_{16}$ & 0.051 & 8 & 0.011 & 36 \\
\hline & & & $C_{17}$ & 0.119 & 6 & 0.026 & 24 \\
\hline & & & $C_{18}$ & 0.091 & 7 & 0.020 & 33 \\
\hline \multirow[t]{8}{*}{$D_{2}$} & 0.240 & 2 & $C_{21}$ & 0.071 & 8 & 0.017 & 35 \\
\hline & & & $C_{22}$ & 0.120 & 5 & 0.029 & 16 \\
\hline & & & $C_{23}$ & 0.104 & 7 & 0.025 & 26 \\
\hline & & & $C_{24}$ & 0.143 & 3 & 0.034 & 7 \\
\hline & & & $C_{25}$ & 0.148 & 2 & 0.035 & 3 \\
\hline & & & $C_{26}$ & 0.116 & 6 & 0.028 & 19 \\
\hline & & & $C_{27}$ & 0.137 & 4 & 0.033 & 11 \\
\hline & & & $C_{28}$ & 0.162 & 1 & 0.039 & 1 \\
\hline
\end{tabular}


Table 10. Cont.

\begin{tabular}{|c|c|c|c|c|c|c|c|}
\hline Dimension & Local Weight & Rank & Criteria & Local Weight & Rank & Global Weight & Rank \\
\hline \multirow[t]{8}{*}{$D_{3}$} & 0.245 & 1 & $C_{31}$ & 0.140 & 3 & 0.034 & 8 \\
\hline & & & $C_{32}$ & 0.120 & 5 & 0.029 & 14 \\
\hline & & & $C_{33}$ & 0.109 & 7 & 0.027 & 22 \\
\hline & & & $C_{34}$ & 0.142 & 2 & 0.035 & 6 \\
\hline & & & $C_{35}$ & 0.119 & 6 & 0.029 & 15 \\
\hline & & & $C_{36}$ & 0.086 & 8 & 0.021 & 30 \\
\hline & & & $C_{37}$ & 0.139 & 4 & 0.034 & 9 \\
\hline & & & $C_{38}$ & 0.145 & 1 & 0.035 & 2 \\
\hline \multirow[t]{6}{*}{$D_{4}$} & 0.163 & 4 & $C_{41}$ & 0.154 & 5 & 0.025 & 25 \\
\hline & & & $C_{42}$ & 0.165 & 3 & 0.027 & 20 \\
\hline & & & $C_{43}$ & 0.213 & 1 & 0.035 & 5 \\
\hline & & & $C_{44}$ & 0.165 & 4 & 0.027 & 21 \\
\hline & & & $C_{45}$ & 0.176 & 2 & 0.029 & 17 \\
\hline & & & $C_{46}$ & 0.127 & 6 & 0.021 & 31 \\
\hline \multirow[t]{6}{*}{$D_{5}$} & 0.133 & 5 & $C_{51}$ & 0.155 & 5 & 0.021 & 32 \\
\hline & & & $C_{52}$ & 0.147 & 6 & 0.020 & 34 \\
\hline & & & $C_{53}$ & 0.160 & 4 & 0.021 & 29 \\
\hline & & & $C_{54}$ & 0.169 & 3 & 0.022 & 28 \\
\hline & & & $C_{55}$ & 0.198 & 1 & 0.026 & 23 \\
\hline & & & $C_{56}$ & 0.171 & 2 & 0.023 & 27 \\
\hline
\end{tabular}

Table 11. Confidence in the ranking of dimensions.

\begin{tabular}{cccccc}
\hline & $\boldsymbol{D}_{\mathbf{1}}$ & $\boldsymbol{D}_{\mathbf{2}}$ & $\boldsymbol{D}_{\mathbf{3}}$ & $\boldsymbol{D}_{\mathbf{4}}$ & $\boldsymbol{D}_{\mathbf{5}}$ \\
\hline$D_{1}$ & - & $27.02 \%$ & $22.36 \%$ & $98.40 \%$ & $99.99 \%$ \\
$D_{2}$ & $72.97 \%$ & - & $44.29 \%$ & $99.58 \%$ & $100.00 \%$ \\
$D_{3}$ & $77.64 \%$ & $55.71 \%$ & - & $99.70 \%$ & $100.00 \%$ \\
$D_{4}$ & $1.60 \%$ & $0.42 \%$ & $0.30 \%$ & - & $92.33 \%$ \\
$D_{5}$ & $0.01 \%$ & $0.00 \%$ & $0.00 \%$ & $7.68 \%$ & - \\
\hline
\end{tabular}

\section{Results and Discussion}

The analysis results of this study can be found in Table 10. Our analysis results echo Chang et al.'s [27] research. They also believe that the establishment of campus protection measures at a college is an important task. We reviewed many literatures [27-31] on campus epidemic prevention and summarized specific findings. The result of this study can provide some management suggestions for the coordinators and decision-makers of campus epidemic prevention. Figures 1 and 2 are drawn based on the results of Table 10 . Figure 1 is a radar chart showing the local weights of the criteria. The larger the local weight, the higher the importance of the criterion in the corresponding dimension. In addition, Figure 2 is a bar graph constructed by the global weights of the criteria. It is a comprehensive evaluation system (taking into account the weight of dimensions). Decision makers can quickly understand which criteria are important based on these visualizations.

This study discusses the first three important criteria for each dimension. In terms of the establishment of epidemic prevention organizations and control of campus epidemic $\left(D_{1}\right)$, the top three with the highest weights are the establishment of campus epidemic prevention team $\left(C_{11}\right)$, the consolidation of campus epidemic prevention status $\left(C_{12}\right)$, and the establishment of the campus epidemic prevention information system $\left(C_{13}\right)$. Schools must systematically plan a campus epidemic prevention organization to coordinate and assign the members of each organization to collect COVID-19-related information, and to formulate epidemic prevention policies and responses. The stable operation of the epidemic prevention team can effectively implement management and supervise all faculty, staff, and students on campus, which helps to control the epidemic and reduce the risk of infection. In addition, the accurate collection of the overall campus epidemic prevention 
status can immediately control the infection cases of all faculty, staff, and students, so as to avoid the rapid spread of the virus without knowing it. The campus epidemic prevention information system must achieve transparency in epidemic information so that all faculty, staff, and students can understand the overall situation of the school epidemic, which is conducive to calming faculty, staff, and students on the campus and easing panic over the epidemic. The establishment of an information system also helps government health agencies know about the impact of the epidemic situation of colleges and universities [28].

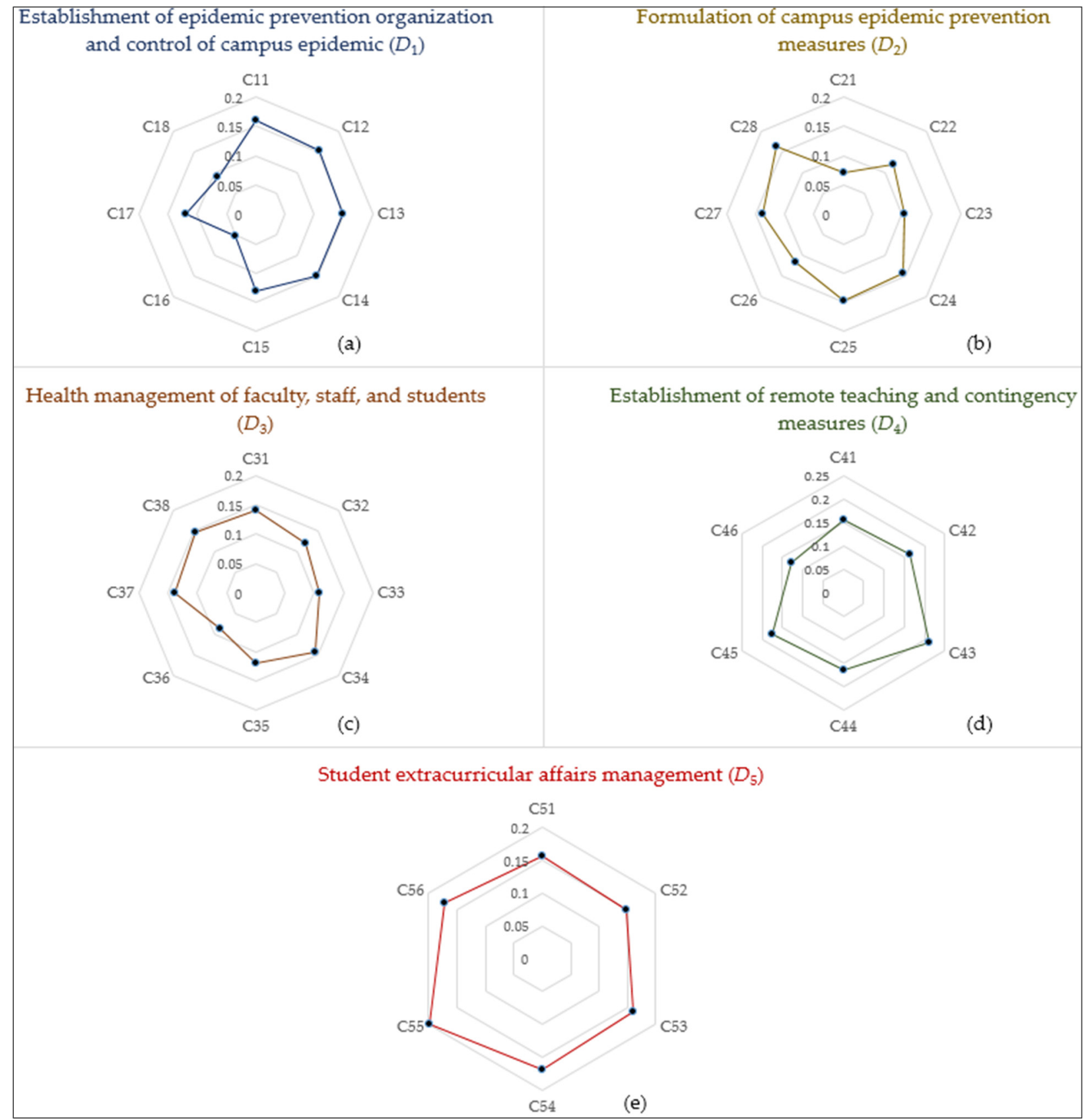

Figure 1. (a) The local weights of the criteria under $D_{1}$; (b) The local weights of the criteria under $D_{2}$; (c) The local weights of the criteria under $D_{3} ;(\mathbf{d})$ The local weights of the criteria under $D_{4} ;(\mathbf{e})$ The local weights of the criteria under $D_{5}$. 


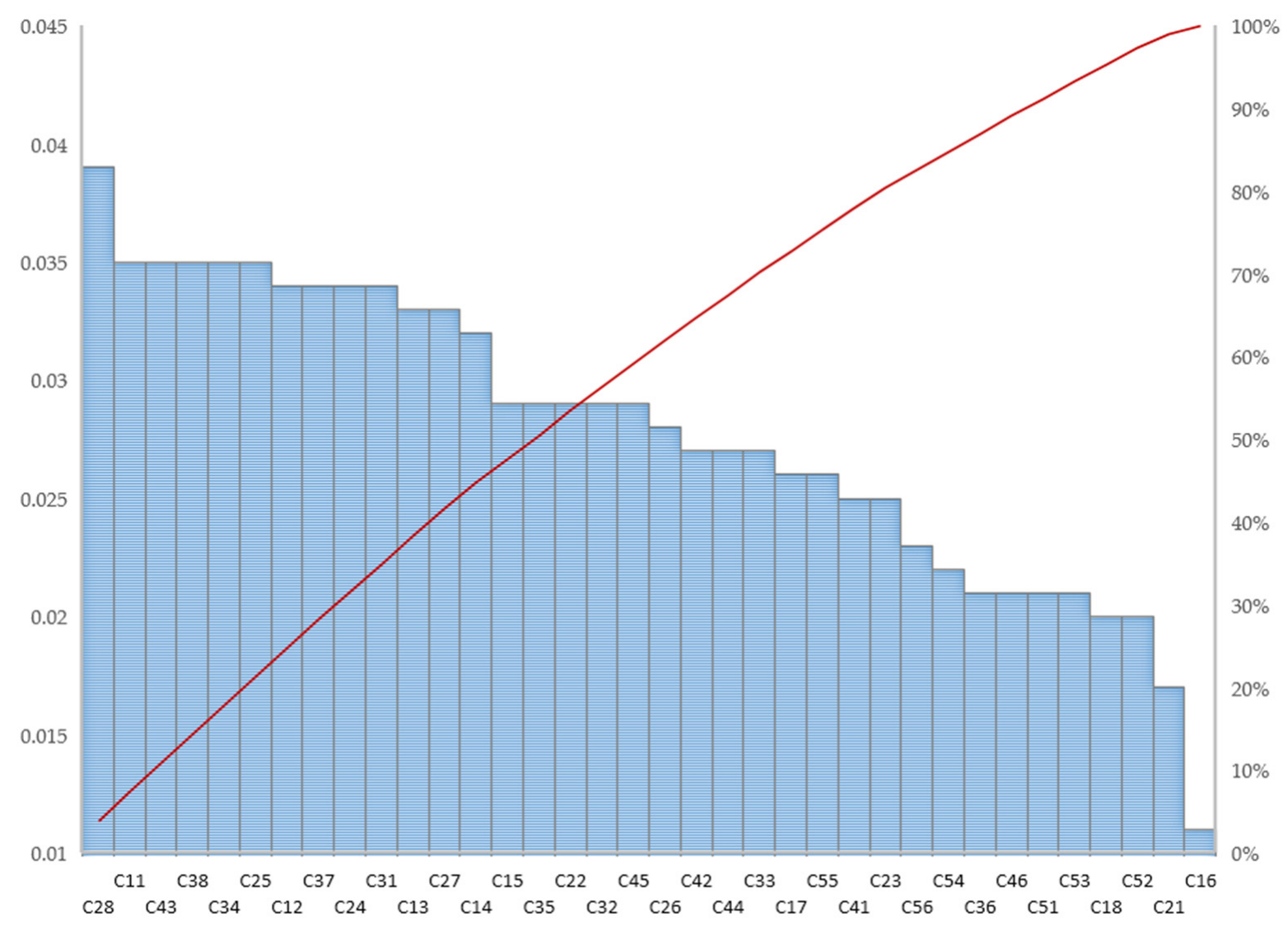

Figure 2. The global weights and priorities of the criteria.

In the formulation of campus epidemic prevention measures $\left(D_{2}\right)$, campus environment disinfection $\left(C_{28}\right)$ is particularly important. Alcohol and sodium hypochlorite are used to dehydrate, coagulate, and denature the protein of bacteria or viruses to inhibit the normal function of the protein or destroy its structure to achieve the disinfection effect. This eliminates the virus remaining on public goods and reduces the risk of infection in contact with objects. COVID-19 is also spread by respiratory droplets or direct contact. Therefore, indoor space ventilation management $\left(C_{25}\right)$ is also an important item for epidemic prevention. Although there is no way to completely filter all COVID-19 virus strains through the central air-conditioning circulation system, having a good ventilation environment can effectively reduce the density of the virus and reduce the risk of infection. Anti-epidemic measures, such as access control and body temperature measurement, help screen personnel entering. For the external visitor access management $\left(C_{24}\right)$, through the real-name system and reserved personal epidemic prevention information, it can reduce the entry of outsiders into the campus, which can the risk of external infection on the campus. If there is an epidemic situation, it will help the school to track it afterwards [27].

In terms of health management of faculty, staff, and students $\left(D_{3}\right)$, putting those in close contacts with confirmed cases in quarantine $\left(C_{38}\right)$ is to first classify close contacts and general contacts. Under the premise of taking protective measures, suspicious cases and close contacts are transferred to quarantine rooms for detailed investigation to prevent crossinfection. To prevent the spread of COVID-19, it can be done through the strengthening of personal hygiene practices $\left(C_{34}\right)$, such as washing hands frequently, wearing masks, and avoiding crowded places. Good hygiene practices to strengthen self-cleaning can help reduce the chance of infection. For people with symptoms of fever, cough, dizziness, fatigue, headache, diarrhea, and difficulty breathing, relevant notification units and channels inside and outside the school should be drawn up. Notification of suspected/confirmed cases $\left(C_{31}\right)$ to campus epidemic prevention units or government health units helps control the spread of the epidemic and reduce the risk of infection $[28,30]$. 
In terms of remote teaching and contingency measures $\left(D_{4}\right)$, the formulation of measures for the management of foreign students $\left(C_{43}\right)$ is to give priority to relaxing the entry restriction of foreign students from countries with less severe epidemics. Through formulating relevant policies of overseas epidemic prevention and isolation equipment, the standard operating procedures for airport border control, epidemic prevention transportation, and quarantine venues are implemented to ensure that the rights of overseas students are not affected while conducting the epidemic prevention operations. The formulation of contingency measures for admissions interview and selection $\left(C_{45}\right)$ refers to the preparation of relevant contingency measures, such as interview and selection for admissions through video communications, or meeting discussions through videoconference, when people encounter irresistible matters so that campus activities will not be delayed, suspended, or terminated. Contingency measures help prevent school administration from shutting down due to the epidemic. If the school has two confirmed cases, all of the classes must be suspended $\left(C_{42}\right)$ to avoid the spread of the epidemic on campus, and to maintain the safety and health of students and staff on campus. The government has stipulated that if a student or instructor is listed as a confirmed case on campus, all classes the student takes or classes taught by the instructor will be suspended. If more than two instructors or students are listed as confirmed cases, the school will suspend all classes. The number of infected persons determines the number of days of class suspension [28].

In terms of student extracurricular affairs management $\left(D_{5}\right)$, the school uses internships to expose students to workplace work early. However, due to the epidemic situation, many overseas internship opportunities have been suspended. It is necessary to re-formulate responding measures (abroad) of relevant overseas internship $\left(C_{55}\right)$ to modify the measures for overseas internships and back-to-Taiwan internships, so that students can have corresponding supporting measures during the epidemic. In response to reported cases, suspected cases, or confirmed cases on campus, formulation of home quarantine measures for dormitories on campus $\left(C_{56}\right)$ is proposed to plan and adjust ahead of time which dormitories on campus are quarantine dormitories and which dormitories are nonquarantine dormitories to ensure that the campus provides effective quarantine dormitories and at the same time protects the original boarding students' right to stay. In addition to formulating contingency measures for oversea internships, it also needs to formulate internship responding measures for domestic internships (domestic) $\left(C_{54}\right)$. By adjusting and delaying students' domestic internship opportunities, other courses and plans are arranged to overcome the inconvenience during the epidemic [31].

For the overall results, the top 10 epidemic prevention works can be ranked through the Bayesian BWM analysis as $C_{28} \succ C_{38} \succ C_{25} \succ C_{11} \succ C_{43} \succ C_{34} \succ C_{24} \succ C_{31} \succ C_{37} \succ C_{12}$. The priority of the criteria can provide a basis for colleges and universities to establish epidemic prevention measures. As long as the epidemic prevention is done well, colleges and universities can reopen their campuses safely and as soon as possible [29].

\section{Conclusions}

The severe epidemic of COVID-19 has not yet slowed down, and many countries are still suffering from the spread of the virus. This study hopes to use Taiwan's experience in epidemic prevention to provide advice on epidemic prevention in colleges and universities around the world. This research proposes a framework for the prevention of COVID-19 by colleges and universities. We surveyed 32 experts who have contributed to COVID19 campus epidemic prevention and used the MCDM model to convert their valuable experience into a systematic epidemic prevention framework. Initially, there were 52 criteria for epidemic prevention work, and the final 36 criteria were determined through many expert discussions and screenings. Bayesian BWM technology is applied to simplify the traditional form of pairwise comparisons to obtain more reliable results. Besides, Bayesian BWM is based on the idea of statistical inference to integrate the opinions of multiple experts to obtain a set of optimal group criterion weights. The people in charge of epidemic prevention or decision-makers can draw up the priority of epidemic prevention work 
according to the weight. Finally, the research procedure in this paper is reproducible and can be used as a reference for other epidemic prevention organizations.

This study also has some limitations. The limitations can provide further development for the MCDM field and epidemic prevention work. One limitation is that the current case study is based on colleges and universities in Taiwan, and the experts interviewed are those in charge of epidemic prevention in Taiwan. The discussion can be extended to multiple countries in the future. Another limitation is that the current research has not yet explored the interrelationship and interdependence among those epidemic prevention works. We suggest that future work can try to explore the causal relationship among the criteria to understand which epidemic prevention measures are the main factors that affect others, and which works will be affected by others. In the future, this study can be combined with the decision-making trial and evaluation laboratory (DEMATEL) technique to discuss the above issues. Finally, the discussion of COVID-19 prevention work can be extended to other areas, such as residential communities, industrial parks, and tourist areas.

Author Contributions: W.-C.J.H. wrote the paper and administrated the project, H.-W.L. co-wrote and designed the research, C.-C.Y. collected the data and revised the paper. All authors have read and agreed to the published version of the manuscript.

Funding: This research received no external funding.

Institutional Review Board Statement: Not applicable.

Informed Consent Statement: Not applicable.

Data Availability Statement: Not applicable.

Conflicts of Interest: The authors declare no conflict of interest.

\section{References}

1. Crawford, J.; Butler-Henderson, K.; Rudolph, J.; Malkawi, B.; Glowatz, M.; Burton, R.; Magni, P.; Lam, S. COVID-19: 20 countries' higher education intra-period digital pedagogy responses. J. Appl. Learn. Teach. 2020, 3, 1-20.

2. Favale, T.; Soro, F.; Trevisan, M.; Drago, I.; Mellia, M. Campus traffic and e-Learning during COVID-19 pandemic. Comput. Netw. 2020, 176, 107290. [CrossRef]

3. Mishra, L.; Gupta, T.; Shree, A. Online teaching-learning in higher education during lockdown period of COVID-19 pandemic. Int. J. Educ. Res. Open 2020, 1, 100012. [CrossRef]

4. Cirrincione, L.; Plescia, F.; Ledda, C.; Rapisarda, V.; Martorana, D.; Moldovan, R.E.; Theodoridou, K.; Cannizzaro, E. COVID-19 pandemic: Prevention and protection measures to be adopted at the workplace. Sustainability 2020, 12, 3603. [CrossRef]

5. Yang, J.-J.; Lo, H.-W.; Chao, C.-S.; Shen, C.-C.; Yang, C.-C. Establishing a Sustainable Sports Tourism Evaluation Framework with a Hybrid Multi-Criteria Decision-Making Model to Explore Potential Sports Tourism Attractions in Taiwan. Sustainability 2020, 12, 1673. [CrossRef]

6. Lo, H.-W.; Shiue, W.; Liou, J.J.H.; Tzeng, G.-H. A hybrid MCDM-based FMEA model for identification of critical failure modes in manufacturing. Soft Comput. 2020, 24, 15733-15745. [CrossRef]

7. Mohammadi, M.; Rezaei, J. Bayesian best-worst method: A probabilistic group decision making model. Omega 2020, 96, 102075. [CrossRef]

8. Wolff, L.-A. Sustainability Education in Risks and Crises: Lessons from Covid-19. Sustainability 2020, 12, 5205. [CrossRef]

9. Taiwan Ministry of Education. The Outlines of the Prevention and Treatment of Severe and Special Infectious Pneumonia in Colleges and Universities. 2020. Available online: https: / / www.edu.tw /News_Content.aspx?n=0217161130F0B192\&s=E75749E5 FBC8D181 (accessed on 30 December 2020).

10. Taiwan Centers for Disease Control. CECC Announces Social Distancing Measures for COVID-19. 2020. Available online: https:/ / www.cdc.gov.tw/En/Bulletin/Detail/kM0jm-IqLwNBeT6chKk_wg?typeid=158 (accessed on 30 December 2020).

11. Xu, C.; Jin, J.; Song, J.; Yang, Y.; Yao, M.; Zhang, Y.; Zhao, R.; Chen, Z. Application of refined management in the prevention and control of coronavirus disease 2019 epidemic in non-isolated areas of a general hospital. Int. J. Nurs. Sci. 2020, 7, 143-147. [CrossRef]

12. Tran, B.X.; Nguyen, H.T.; Pham, H.Q.; Le, H.T.; Vu, G.T.; Latkin, C.A.; Ho, C.S.H.; Ho, R.C.M. Capacity of local authority and community on epidemic response in Vietnam: Implication for COVID-19 preparedness. Saf. Sci. 2020, 130, 104867. [CrossRef]

13. Ge, T.; Lu, Y.; Zheng, S.; Zhuo, L.; Yu, L.; Ni, Z.; Zhou, Y.; Ni, L.; Qu, T.; Zhong, Z. Evaluation of disinfection procedures in a designated hospital for COVID-19. Am. J. Infect. Control. 2020, in press. [CrossRef]

14. Liu, X.; Chang, Y.-C. An emergency responding mechanism for cruise epidemic prevention-Taking COVID-19 as an example. Mar. Policy 2020, 119, 104093. [CrossRef] [PubMed] 
15. Moore, L.D.; Robbins, G.; Quinn, J.; Arbogast, J.W. The impact of COVID-19 pandemic on hand hygiene performance in hospitals. Am. J. Infect. Control. 2021, 49, 30-33. [CrossRef]

16. Hu, Y.; Wang, L.; Hu, S.; Fang, F. Facility-Level Case Report of Nursing Care Processes for Patients With Suspected 2019 Novel Coronavirus Disease in Shanghai, China. J. Emerg. Nurs. 2020, 46, 898-906. [CrossRef] [PubMed]

17. Van Nguyen, D.; Pham, G.H.; Nguyen, D.N. Impact of the Covid-19 pandemic on perceptions and behaviors of university students in Vietnam. Data Brief 2020, 31, 105880. [CrossRef] [PubMed]

18. Gomez, E.; Azadi, J.; Magid, D. Innovation Born in Isolation: Rapid Transformation of an In-Person Medical Student Radiology Elective to a Remote Learning Experience During the COVID-19 Pandemic. Acad. Radiol. 2020, 27, 1285-1290. [CrossRef]

19. Ocampo, L.; Yamagishi, K. Modeling the lockdown relaxation protocols of the Philippine government in response to the COVID-19 pandemic: An intuitionistic fuzzy DEMATEL analysis. Socio Econ. Plan. Sci. 2020, 72, 100911. [CrossRef] [PubMed]

20. Ocampo, A.C.G.; Reyes, M.L.; Chen, Y.; Restubog, S.L.D.; Chih, Y.-Y.; Chua-Garcia, L.; Guan, P. The role of internship participation and conscientiousness in developing career adaptability: A five-wave growth mixture model analysis. J. Vocat. Behav. 2020, 120, 103426. [CrossRef]

21. Lagiewski, R.; Barron, P.; Leask, A. The effect of exporting hospitality and tourism degrees overseas on the home campus: A con-ceptual model. J. Hosp. Leis. Sport Tour. Educ. 2019, 24, 211-222. [CrossRef]

22. Brooks, S.K.; Webster, R.K.; Smith, L.E.; Woodland, L.; Wessely, S.; Greenberg, N.; Rubin, G.J. The psychological impact of quarantine and how to reduce it: Rapid review of the evidence. Lancet 2020, 395, 912-920. [CrossRef]

23. Rezaei, J. Best-worst multi-criteria decision-making method. Omega 2015, 53, 49-57. [CrossRef]

24. Chen, Z.; Wang, X.; Peng, J.; Zhang, H.; Wang, J. An integrated probabilistic linguistic projection method for MCGDM based on ELECTRE III and the weighted convex median voting rule. Expert Syst. 2020, 37, 12593. [CrossRef]

25. Guo, S.; Zhang, W.; Gao, X. Business Risk Evaluation of Electricity Retail Company in China Using a Hybrid MCDM Method. Sustainability 2020, 12, 2040. [CrossRef]

26. Kruschke, J. Doing Bayesian Data Analysis: A Tutorial with R, JAGS, and Stan; Academic Press: Cambridge, MA, USA, 2014.

27. Chang, T.C.; Lin, M.Y.; Huang, J.C.; Yen, C.T.; Li, C.H.; Jan, W.C.; Huang, H.Y.; Liu, C.L.; Chen, Y.J. The First 100 Days: Establishment and Effectiveness of Campus Protection Measures at a College during the COVID-19 Pandemic. Healthcare 2020, 8, 308. [CrossRef]

28. Cao, W.; Fang, Z.; Hou, G.; Han, M.; Xu, X.; Dong, J.; Zheng, J. The psychological impact of the COVID-19 epidemic on college students in China. Psychiatry Res. 2020, 287, 112934. [CrossRef] [PubMed]

29. Cheng, S.-Y.; Wang, C.J.; Shen, A.C.-T.; Chang, S.-C. How to Safely Reopen Colleges and Universities During COVID-19: Experiences from Taiwan. Ann. Intern. Med. 2020, 173, 638-641. [CrossRef]

30. Walke, H.T.; Honein, M.A.; Redfield, R.R. Preventing and Responding to COVID-19 on College Campuses. JAMA 2020, 324, 1727-1728. [CrossRef] [PubMed]

31. Aguilera-Hermida, A.P. College students' use and acceptance of emergency online learning due to COVID-19. Int. J. Educ. Res. Open 2020, 1, 100011. [CrossRef] 